\title{
Impact of Migration on the Eating Habit and Physical Activity Patterns among Saudi Students living in South Korea
}

\author{
Noor A. Hakim, $\mathrm{PhD}^{1}$ \\ ${ }^{1}$ Clinical Nutrition Department, Faculty of Applied Medical Sciences, King Abdulaziz University, Jeddah, KSA \\ Correspondence: Noor A. Hakim, Clinical Nutrition Department, Faculty of Applied Medical Sciences, King \\ Abdulaziz University, Jeddah, KSA.
}

Received: October 7, 2020 Accepted: December 8, 2020 Online Published: December 23, 2020

doi:10.5539/gjhs.v13n2p48 URL: https://doi.org/10.5539/gjhs.v13n2p48

\begin{abstract}
This study investigates the effect of migration on eating habits and physical activity patterns of Saudi migrants living in South Korea. A cross-sectional study was conducted, and an online survey was prepared to assess participants' demographic details, including; eating habits and physical activity pattern compared to pre-migration among 198 Saudi students. Data was analyzed through descriptive statistics and chi square. Saudi migrant students practice healthy habits such as; low frequency consumption of snacks and regular exercise habits. No significant difference was observed in the number and type of meal taken per day between the participants who lived less than three years in South Korea, in comparison to those who were living for more than three years. A significant increase in excessive exercise among students who lived in South Korea for more than three years in contrast to the students who lived less than three years. Findings suggested that more attention is needed to identify the nutritional need of international students living in South Korea.
\end{abstract}

Keywords: culture, food, immigrants, Saudi Arabia, dietary pattern, physical activity

\section{Introduction}

The increasing globalization has directed students to migrate to other countries for pursuing further education, which ultimately increases their cross-cultural perceptions and preferences specifically towards food and lifestyle. Various studies demonstrated the developing change in the food habits, specifically in case when one migrates to a new country. This process of developing changes in food habits is defined as dietary acculturation (Aljaroudi ,2018; Britain, 2011; Casali, 2018) where the moving group adopts to new food choices and patterns that may lead to healthier or unhealthier habits. According to Aljaroudi, (2018) dietary acculturation is a complex process and addresses the change in eating habits developed with the passage of time and exposure to a new culture.

On reviewing past literature, it has been found that only a few studies focused on the change in eating habits and food preference of the migrants (Bharmal, 2018; Fadzlillah, 2011). Some studies suggested that change in the food preferences were due to the challenges faced after migration, which include unavailability and high prices for traditional food, few cooking options, altered lifestyle and change in work patterns; this change may lead to dietary adjustment that pose significant changes in health and food security (Aljaroudi, 2018; Brittin, 2011; Casali, 2015; Bharma, 2015; Fadzlillah, 2011; Tarraf, 2017). However, this remains as an explored dimension for the Arab immigrants. Fadzlillah et al., (2011) explains that Arab migrants faced significant difficulties in finding appropriate food that match their requirement of whether the food available is as per the Islamic law that only permits halal food consumption.

Concerns of migrants regarding unavailability of familiar food and adaptation to environmental change affects their eating habit, while requiring certain efforts and adjustments based on individual level of acceptance to change (Sucher, 2016). The individual adaptation of a new culture varies depending on factors, such as personal background which refers to how likely that person perceives the new culture, followed by the time required to adapt the new culture. Furthermore, the course of time is another important indicator for providing information regarding how comfortable the migrant is to accept the new culture, leading towards the development of a comfortable environment which facilitates their purpose of migration such as; provision of health-related treatments, work or educational process. Individual adaptation to a new food culture has been shown by other studies too, which indicated that sometimes people tend to respond positively due to personal admiration or viewing the new culture as superior (Sucher, 2016). While others explained that exposure to a new culture and its 
impact on eating habits could lead to individual adaptation to new food (Holmboe-Ottesen \& Wandel, 2012). It was further indicated that timely adjustments to new culture may be due to familiarities in food and ingredients that facilitate modification. Thomas et al., (2016) shows that food/diet serves as a strategy to integrate into a new environment and culture.

This is also true for immigrants in Korea, as it is confronted with the increase in the number of immigrants particularly from developing countries where it was 6,409 in 1987, 700,000 in 2011 and 1.8 million in 2015 (MacroTrends, 2019; Torneo, 2016). This has led to the alteration of the host country, along with the changes in the immigrants as well. One such aspect is the change in behavior, which acquires an acculturation process, where immigrants' traditional food-related values and behaviors shift to those as in the host country (Aljaroudi, 2018). Various studies recognized a change in immigrants' food choices and their eating habits (Cho, 2010; Kweon, 2006). For instance, Kweon (2006) reported altered eating habits and lifestyle among Chinese students and the Chinese staff living in Korea, due to the appealing taste of Korean food. Similar results were reported by Cho, (2010) concerning Malaysian-Korea immigrants, where various behavioral changes were observed in Malaysian population regarding their food preferences particularly for the two items, i.e., Kimchi and Bulgogi. Guendelman et al., (2011) showed that immigrants' adaptation to a new culture, lifestyle and acculturative stress influenced their eating habits and food choices.

Despite the purpose of moving from home country, change in the environment definitely affects personal choices and eating habits at any level. There is a large number of Saudi residents that prefer migrating to other countries for educational purposes. However, the overall number of Saudi Students enrolled in global universities were 170,000 in the fall of 2011-2012, which reached 200,000 students in the year 2012-2013 (Taylor, 2014). The most targeted countries of Saudi students are US, UK, Canada, Australia, Japan and South Korea (Cultural Mission of Saudi Arabia in South Korea). However, in the last 15 years, South Korea has gained significant attention specifically from Middle Eastern countries, due to their exposure to Korean dramas \& music, industrialized products and advance system of education which has attracted the attention of Saudi population to explore the Korean culture. Following this, South Korea has been recognized as one of the top destinations for Saudi students.

There is very limited information on behavioral and food habits among the migrated population especially those who move for temporary duration. The main objective of this study is to investigate the influence of Korean food and culture on Saudi migrants and how it can affect their eating habits. It is already known that college-going students are highly unhealthy due to unwholesome eating habits, resulting in weight gain and obesity (Huang, 2003). However, in the last decade there is a high trend of being health-conscious in Saudi culture where organic, low calorie-nutritious meals and home-based cooked food has increased dramatically in the market. Besides, the increased number of exercise centers in the Kingdom make it difficult to expect the shared common behaviors among the migrants. Since Korean food reflects the culture where it symbolizes care, beauty, harmonization and patience, (Chung, 2016) accepting Korean food indicates harmonization with the new culture. Therefore, this study investigates the impact of Korean eating habits on Saudi migrants to reveal issues and difficulties that students might face in changing countries and culture. Effective understanding of such issues may prepare educators to reduce the social/dietary expected issues that they might face during their education journey. This study will also explain the student's perception of changed food habits after migration.

\section{Methods}

\subsection{Study Design and Recruitment}

Saudi students who had been living in South Korea during 2015 were approached. Participants were contacted via email to fill out an online survey. The Saudi Cultural Mission was approached in this regard by emailing all the Saudi students. Interested students reposed by approving the invitation and answering the survey. The power sample of this study is based on Saudi students living in South Korea, resulting in the final power sample of about 100 participants.

\subsection{Measurements}

The Principal investigator was given the charge to design the main online survey. The questionnaire included personal details like age, years of stay in South Korea, gender, educational degree, home country and options of Saudi region where they belong to. Questions related to student's eating habits, their physical activity pattern and what change that participants believed happened since they moved to South Korea were included in the survey. In terms of their eating habits, questions such as; how many meals they ate daily; how often they ate Korean food, cultural food and international food (including Italian, American, or Indian) etc. were added. In addition, they were asked how often they opt for a home cooked meal and their preferences of eating Korean food. To assess the 
amount of food type consumed, students were asked to rank the amount of food type that they eat from 1 to 3 ; where 1 represented lowest amount and 3 represented highest amount. Moreover, participants were asked to evaluate their preference for eating Korean food from restaurants, deli food markets, or food streets.

The questionnaire was designed in such a manner where limiting factors were also taken into consideration, such as; participants were asked about their choices in terms of halal or restricted food in Korean cuisine. Moreover, shopping habits were also considered as good evidence of personal preferences and habits of purchasing ingredients from the Korean market, International market, or the Arab market (Taraff, 2017). Information gained from this survey helped in the assessment of participant's habits in terms of eating and physical activities, as well as, differences in behaviors between the two periods of living groups (group 1 who live $<3$ years and group 2 who live $\geq 3$ years long).

\subsection{Ethical Approval and Statistics}

Ethical approval from the Research Ethics Committee, Faculty of Medicine, and King Abdulaziz University have been obtained with Reference No 567-17. The data of the study was analyzed by using Statistical Package of Social Sciences (SPSS) 16.0. Data was represented in the form of descriptive statistics and chi square analysis to investigate the effect of time duration on participants behaviors

\section{Results}

\subsection{Sample Characteristics}

Table 1 shows the demographic information of the study participants, where most of them were male $(68.4 \%)$, and the highest age group was between 21-29 years old (60.6\%) followed by ages 30-39 years old (27.8\%). 38.9\% of Saudi students had been living in South Korea for the last 3-4 years, while 37.4\% had been living in South Korea for the last 1-2 years $(37.4 \%)$. Since this study used a cut off value of three years to compare the behavioral differences between the groups, based on the length period of their migration, no significant differences between the distribution groups $(\mathrm{p}=0.92, \mathrm{t}=1.21)$ were found. As 95(48\%) participants lived in South Korea for less than 3 years and $103(52.1 \%)$ participants lived in South Korean for 3 years and more.

Table 1. Demographic Information of the Study Subjects $(\mathrm{n}=198)$

\begin{tabular}{lll}
\hline & $\mathrm{n}$ & $\mathrm{N} \%$ \\
\hline Age & 10 & $5.1 \%$ \\
$18-20$ & 120 & $60.6 \%$ \\
$21-29$ & 55 & $27.8 \%$ \\
$30-39$ & 9 & $4.5 \%$ \\
$40-49$ & 4 & $2.0 \%$ \\
$50-59$ & 0 & $0.0 \%$ \\
60 or older & & \\
\hline How long have you lived in South Korea & 21 & $10.6 \%$ \\
less than one year & 74 & $37.4 \%$ \\
$1-2$ years & 77 & $38.9 \%$ \\
$3-4$ years & 10 & $5.1 \%$ \\
$4-5$ years & 16 & $8.1 \%$ \\
more than 5 years & & $68.4 \%$ \\
\hline Gender & 134 & $31.6 \%$ \\
male & 62 & \\
female & & $2.0 \%$ \\
\hline Educational degree & 4 & $26.8 \%$ \\
less than high school & 53 & \\
high school or similar & & \\
\hline
\end{tabular}




\begin{tabular}{lll}
\hline diploma or similar & 41 & $20.7 \%$ \\
bachelor degree & 65 & $32.8 \%$ \\
master degree & 12 & $6.1 \%$ \\
PhD & 23 & $11.6 \%$ \\
\hline Original country & & \\
Saudi Arabia (If yes, which area?) & 198 & \\
Riyadh & 48 & $24.2 \%$ \\
Makah & 53 & $26.7 \%$ \\
Medina & 21 & $10.6 \%$ \\
Aseer & 14 & $7.1 \%$ \\
Albaha & 3 & $1.5 \%$ \\
Al-Sharqia & 38 & $19.9 \%$ \\
Hail & 2 & $1.0 \%$ \\
North area & 1 & $0.5 \%$ \\
Al-Qaseem & 3 & $1.5 \%$ \\
Tabouk & 2 & $1.0 \%$ \\
Al-Jouf & 1 & $0.5 \%$ \\
Jezan & 2 & $1.0 \%$ \\
Najran & 1 & $0.5 \%$ \\
others & 2 & $1.0 \%$ \\
\hline
\end{tabular}

\subsection{Dietary Intake}

Figure 1 explains the quantities of each food type consumed by the students. Despite the period length of migration, Students consumed more cultural food on a daily basis 30(15.1\%) as compared to Korean $15(7.5 \%)$ and international food 17(8.5\%). Figure 1 also shows the ranking of food types comparing the three different food types consumed by the Saudi migration in South Korea. 


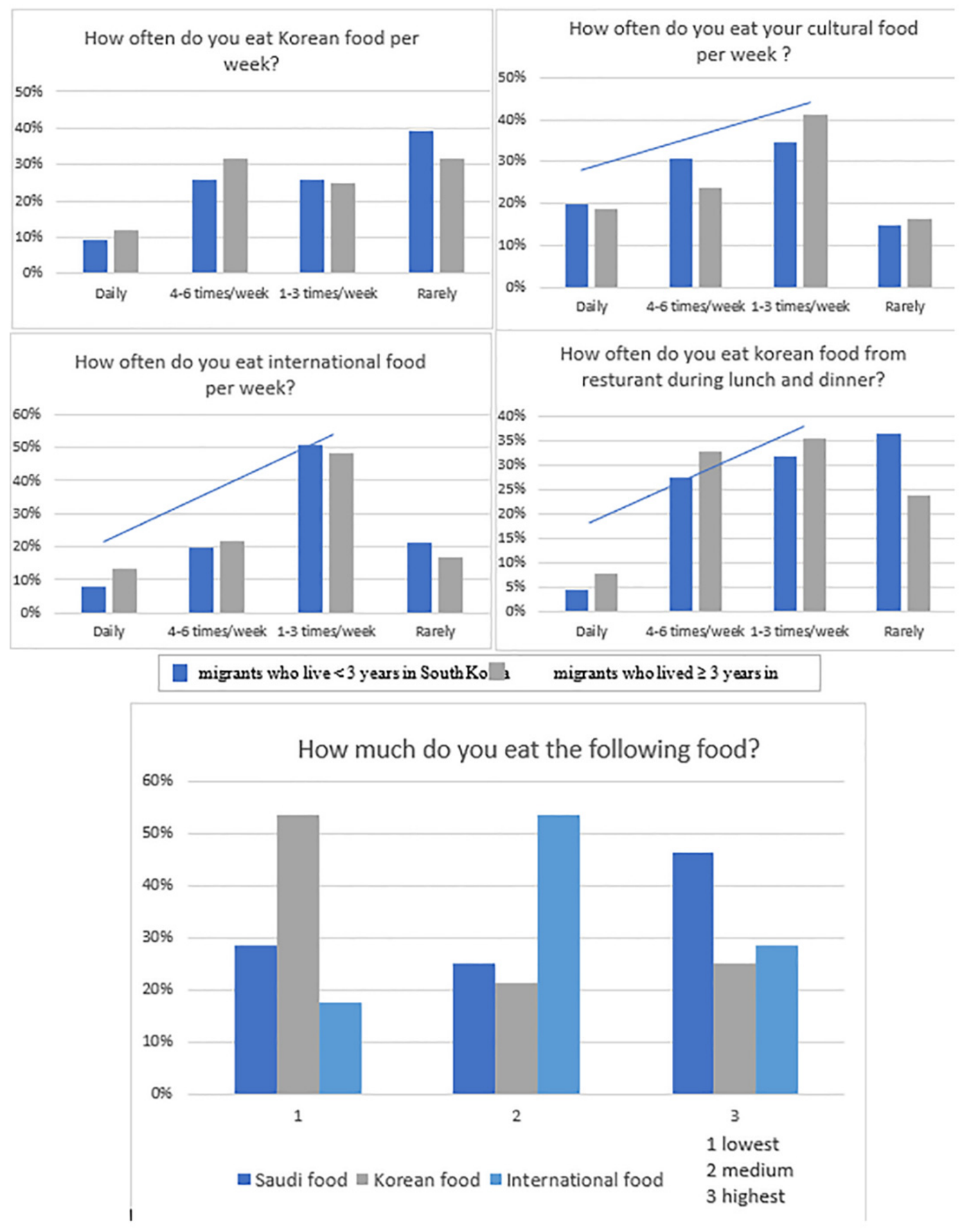




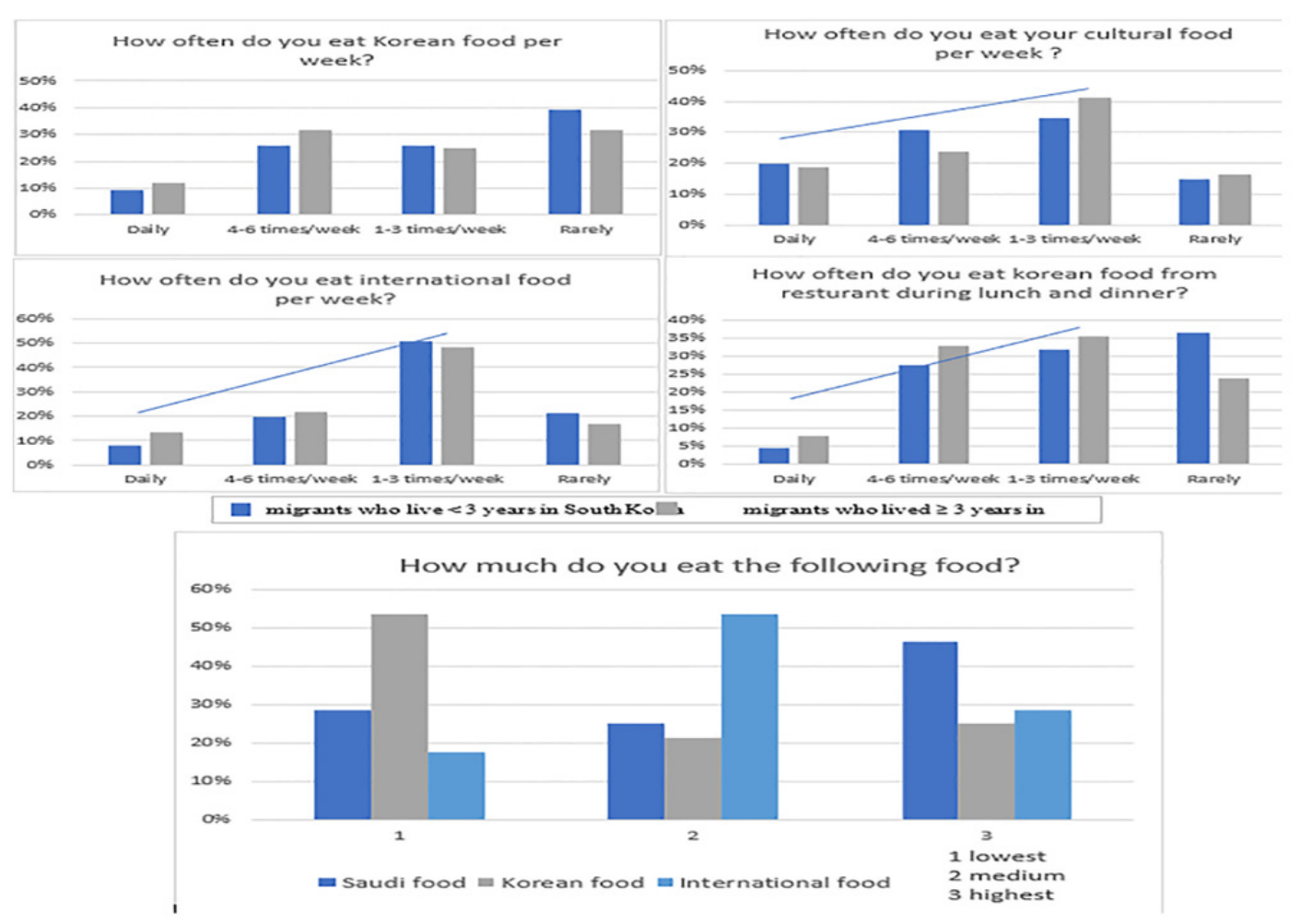

Figure 1. Frequency of Food Consumption and Amount of Food Type Among Saudi Migration Groups

\subsection{Lifestyle Behaviors}

Among the overall participants, 118(59.6\%) were non-smoker and only 42(21.2\%) were smokers. However, there is a significant difference between the two groups; migrants who lived in South Korea for 3 years are more towards smoking in comparison to the group who lived in South Korea for less than 3 years $(p=0.01)$. Moreover, the number of participants who never smoked significantly decreased after staying for 3 years and more in South Korea as compared to migrants who stayed for less than 3 years $(\mathrm{p}=0.01)$. Large proportion of the study's participants don't do excessive exercise on daily basis 77(48.1\%), as respondents indicated that they exercise once $29(18.1 \%)$ or twice $20(12.5 \%)$ and three times $14(8.7 \%)$ per week; the remaining participants exercised 4-7 times per week. Interestingly the highest number of participants who practiced moderate exercises involved 7 times per week 44(27.5\%), and others were in similar numbers like 6 times to no exercise per week. On the other hand, there was no significant difference in the time spent by the two groups when considering walking and doing medium exercises. However, participants who had been living for three years and more were significantly more likely to spend time on excessive exercise in comparison to the participants who lived in Korea for less than three years. Details of exercise and smoking habits among the migration group are shown in Table 2.

Table 2. Eating Habits, Pattern, Choices, Food Consumption, Sources, food shopping habits and sources, smoking and exercise habits Among Saudi Migration Groups ( $\mathrm{n}=198)$

\begin{tabular}{|c|c|c|c|c|c|}
\hline & \multicolumn{4}{|c|}{ Years living in Korea } & \multirow{3}{*}{ P value } \\
\hline & \multicolumn{2}{|c|}{$<3$ years } & \multicolumn{2}{|c|}{3 years or more } & \\
\hline & $\mathrm{n}$ & $\mathrm{N} \%$ & $\mathrm{n}$ & $\mathrm{N} \%$ & \\
\hline \multicolumn{6}{|c|}{ How many meals do you eat daily? } \\
\hline 1 & 3 & $3.9 \%$ & 9 & $10.7 \%$ & \multirow{5}{*}{ NS } \\
\hline 2 & 49 & $64.5 \%$ & 46 & $54.8 \%$ & \\
\hline 3 & 23 & $30.3 \%$ & 26 & $31.0 \%$ & \\
\hline 4 & 0 & $0.0 \%$ & 1 & $1.2 \%$ & \\
\hline 5 & 1 & $1.3 \%$ & 2 & $2.4 \%$ & \\
\hline
\end{tabular}




\begin{tabular}{|c|c|c|c|c|c|}
\hline \multicolumn{6}{|l|}{ Do you eat in between meals? } \\
\hline Yes & 26 & $34.2 \%$ & 21 & $25.0 \%$ & \multirow{3}{*}{ NS } \\
\hline No & 9 & $11.8 \%$ & 16 & $19.0 \%$ & \\
\hline Sometime & 41 & $53.9 \%$ & 47 & $56.0 \%$ & \\
\hline \multicolumn{6}{|l|}{ Do you eat Korean food? } \\
\hline No & 10 & $13.2 \%$ & 8 & $9.5 \%$ & \multirow{6}{*}{ NS } \\
\hline Yes, (How many times per week?) & 66 & $86.8 \%$ & 76 & $90.5 \%$ & \\
\hline Daily or more than 6 times a week & 6 & $9.1 \%$ & 9 & $11.8 \%$ & \\
\hline 4-6 times a week & 17 & $25.8 \%$ & 24 & $31.6 \%$ & \\
\hline 1-3 times a week & 17 & $25.8 \%$ & 19 & $25.0 \%$ & \\
\hline Rarely & 26 & $39.4 \%$ & 24 & $31.6 \%$ & \\
\hline \multicolumn{6}{|c|}{ What is your opinion about Korean food? } \\
\hline Healthy nutritious & 44 & $66.7 \%$ & 50 & $72.5 \%$ & \multirow{7}{*}{ NS } \\
\hline Not healthy & 2 & $3.0 \%$ & 2 & $2.9 \%$ & \\
\hline Delicious & 8 & $12.1 \%$ & 14 & $20.3 \%$ & \\
\hline Unique & 4 & $6.1 \%$ & 14 & $20.3 \%$ & \\
\hline Available & 16 & $24.2 \%$ & 24 & $34.8 \%$ & \\
\hline Cheap & 20 & $30.3 \%$ & 34 & $49.3 \%$ & \\
\hline Other & 14 & $21.2 \%$ & 7 & $10.1 \%$ & \\
\hline \multicolumn{6}{|l|}{ Do you eat your cultural food? } \\
\hline No & 1 & $1.3 \%$ & 4 & $4.8 \%$ & \multirow{6}{*}{ NS } \\
\hline Yes, (How many times per week?) & 75 & $98.7 \%$ & 80 & $95.2 \%$ & \\
\hline Daily & 15 & $20.0 \%$ & 15 & $18.8 \%$ & \\
\hline 4-6 times a week & 23 & $30.7 \%$ & 19 & $23.8 \%$ & \\
\hline 1-3 times a week & 26 & $34.7 \%$ & 33 & $41.3 \%$ & \\
\hline Rarely & 11 & $14.7 \%$ & 13 & $16.3 \%$ & \\
\hline \multicolumn{6}{|c|}{ Do you eat International food (American, Italian and Indian)? } \\
\hline No & 1 & $1.3 \%$ & 1 & $1.2 \%$ & \multirow{6}{*}{ NS } \\
\hline Yes, (How many times per week?) & 75 & $98.7 \%$ & 83 & $98.8 \%$ & \\
\hline Daily & 6 & $8.0 \%$ & 11 & $13.3 \%$ & \\
\hline 4-6 times a week & 15 & $20.0 \%$ & 18 & $21.7 \%$ & \\
\hline $1-3$ times a week & 38 & $50.7 \%$ & 40 & $48.2 \%$ & \\
\hline Rarely & 16 & $21.3 \%$ & 14 & $16.9 \%$ & \\
\hline \multicolumn{6}{|c|}{ How often do you eat homemade food } \\
\hline Always & 17 & $22.4 \%$ & 15 & $17.9 \%$ & \multirow{5}{*}{$\begin{array}{l}x^{2}=8.49 \\
P=0.075\end{array}$} \\
\hline Usually & 36 & $47.4 \%$ & 27 & $32.1 \%$ & \\
\hline Sometimes & 17 & $22.4 \%$ & 26 & $31.0 \%$ & \\
\hline Rarely & 6 & $7.9 \%$ & 13 & $15.5 \%$ & \\
\hline Never & 0 & $0.0 \%$ & 3 & $3.6 \%$ & \\
\hline \multicolumn{6}{|c|}{ How much do you eat from Korean cuisine } \\
\hline lowest amount & 36 & $53.7 \%$ & 37 & $53.6 \%$ & \multirow{3}{*}{ NS } \\
\hline medium amount & 13 & $19.4 \%$ & 16 & $23.2 \%$ & \\
\hline highest amount & 18 & $26.9 \%$ & 16 & $23.2 \%$ & \\
\hline
\end{tabular}




\begin{tabular}{|c|c|c|c|c|c|}
\hline \multicolumn{6}{|l|}{ How much do you eat from your cultural cuisine? } \\
\hline lowest amount & 17 & $25.4 \%$ & 22 & $31.9 \%$ & \multirow{3}{*}{ NS } \\
\hline medium amount & 19 & $28.4 \%$ & 15 & $21.7 \%$ & \\
\hline highest amount & 31 & $46.3 \%$ & 32 & $46.4 \%$ & \\
\hline \multicolumn{6}{|l|}{ How much do you eat from International cuisine? } \\
\hline lowest amount & 14 & $20.9 \%$ & 10 & $14.5 \%$ & \multirow{3}{*}{ NS } \\
\hline medium amount & 35 & $52.2 \%$ & 38 & $55.1 \%$ & \\
\hline highest amount & 18 & $26.9 \%$ & 21 & $30.4 \%$ & \\
\hline \multicolumn{6}{|l|}{ Do you eat lunch or dinner from Korean restaurant? } \\
\hline No & 0 & $0.0 \%$ & 0 & $0.0 \%$ & \multirow{6}{*}{ NS } \\
\hline Yes (If yes, how often?): & 66 & $100 \%$ & 76 & $100 \%$ & \\
\hline Daily & 3 & $4.5 \%$ & 6 & $7.9 \%$ & \\
\hline 4-6 times a week & 18 & $27.3 \%$ & 25 & $32.9 \%$ & \\
\hline $1-3$ times a week & 21 & $31.8 \%$ & 27 & $35.5 \%$ & \\
\hline Rarely & 24 & $36.4 \%$ & 18 & $23.7 \%$ & \\
\hline \multicolumn{6}{|l|}{ Korean food source } \\
\hline Restaurant & 63 & $86.3 \%$ & 79 & $94.0 \%$ & \multirow{5}{*}{ NS } \\
\hline Deli food market & 11 & $15.1 \%$ & 15 & $17.9 \%$ & \\
\hline Street food & 10 & $13.7 \%$ & 10 & $11.9 \%$ & \\
\hline Dorm & 7 & $9.6 \%$ & 13 & $15.5 \%$ & \\
\hline Other & 10 & $13.7 \%$ & 3 & $3.6 \%$ & \\
\hline \multicolumn{6}{|l|}{ What are your choices in Korean food? } \\
\hline tend to choose vegetables-based dishes only & 16 & $21.1 \%$ & 12 & $14.3 \%$ & \multirow{7}{*}{ NS } \\
\hline food based on vegetables and seafood & 40 & $52.6 \%$ & 44 & $52.4 \%$ & \\
\hline $\begin{array}{l}\text { tend to eat food that contain Australian or American } \\
\text { meat }\end{array}$ & 35 & $46.1 \%$ & 43 & $51.2 \%$ & \\
\hline you can't eat Korean food unless it is HALAL & 11 & $14.5 \%$ & 8 & $9.5 \%$ & \\
\hline you avoid pig's products and alcohol & 40 & $52.6 \%$ & 40 & $47.6 \%$ & \\
\hline $\begin{array}{l}\text { there is no limitation or avoidance, you can eat any } \\
\text { Korean ingredients }\end{array}$ & 6 & $7.9 \%$ & 11 & $13.1 \%$ & \\
\hline other & 7 & $9.2 \%$ & 3 & $3.6 \%$ & \\
\hline \multicolumn{6}{|c|}{ Do you buy your food ingredients from Korean markets/supermarkets? } \\
\hline Always & 18 & $23.70 \%$ & 21 & $25.00 \%$ & \multirow{5}{*}{ NS } \\
\hline Usually & 29 & $38.20 \%$ & 29 & $34.50 \%$ & \\
\hline Sometimes & 16 & $21.10 \%$ & 19 & $22.60 \%$ & \\
\hline Rarely & 9 & $11.80 \%$ & 11 & $13.10 \%$ & \\
\hline Never & 4 & $5.30 \%$ & 4 & $4.80 \%$ & \\
\hline \multicolumn{6}{|c|}{ Do you buy your food ingredients from Arabic or International market? } \\
\hline Always & 10 & $13.20 \%$ & 16 & $19.00 \%$ & \multirow{5}{*}{ NS } \\
\hline Usually & 29 & $38.20 \%$ & 21 & $25.00 \%$ & \\
\hline Sometimes & 28 & $36.80 \%$ & 32 & $38.10 \%$ & \\
\hline Rarely & 8 & $10.50 \%$ & 13 & $15.50 \%$ & \\
\hline Never & 1 & $1.30 \%$ & 2 & $2.40 \%$ & \\
\hline \multicolumn{6}{|l|}{ Do you smoke? } \\
\hline yes, currently smoker & 12 & $15.8 \%$ & 30 & $35.7 \%$ & $x^{2}=8.577$ \\
\hline
\end{tabular}




\begin{tabular}{|c|c|c|c|c|c|}
\hline previously smoker & 7 & $9.2 \%$ & 8 & $9.5 \%$ & $\mathrm{P}=0.014$ \\
\hline never smoker & 57 & $75.0 \%$ & 46 & $54.8 \%$ & \\
\hline \multicolumn{6}{|l|}{ Type of exercise and duration } \\
\hline Excessive exercise min/week mean $\pm \mathrm{SE}$ & \multicolumn{2}{|c|}{$55.79 \pm 14.47$} & \multicolumn{2}{|c|}{$131.87 \pm 24.48$} & $\mathrm{P}=0.004$ \\
\hline Medium exercise min/week mean $\pm \mathrm{SE}$ & \multicolumn{2}{|c|}{$287.37 \pm 40.49$} & \multicolumn{2}{|c|}{$265.42 \pm 47.07$} & NS \\
\hline Walking min/week mean $\pm \mathrm{SE}$ & \multicolumn{2}{|c|}{$256.71 \pm 40.85$} & \multicolumn{2}{|c|}{$229.10 \pm 30.82$} & NS \\
\hline
\end{tabular}

\section{Discussion}

This study investigates the eating habits and physical activity patterns of Saudi migrants living in South Korea and explores the differences of eating habits under the effect of course of time. Saudi students who decided to migrate to South Korea for educational purposes during the years 2015-2017 were mostly males in their twenties that were pursuing their undergraduate degree. This study found some good healthy eating practices among Saudi migrants such as low snack intakes, frequent home meal food and regular exercise habits. Findings further reveals unhealthy eating habits due to low frequent meal numbers during the day. However, it is better to increase the number of meals per day to more than two meals with limited calories which might be ideal to regulate the glycemic index and to prevent slow down metabolism during university hours.

This study has not shown dramatic changes in eating of traditional and other cuisine food among the groups, but it is expected to increase since there is more chance for them to eat outside specially after long periods of migration (more than 3 years). The findings of this study are in contrast to the Chinese study where, Chinese residence living in Korea had Korean food quite often, this is probably due to the different background and familiarity among food of Saudi culture compared to Chinese culture (Kweon, 2006). Although Saudi migrants believe that Korean food is healthy, nutritious cheap and easily accessible, it seems that Korean food is not consumed as major food. This is probably due to completely different flavor and difficulty in finding appropriate food and ingredients that match their traditional and Islamic regulation. Unfamiliarity might be another reason, as Korean cuisine is based on low fat content and very rich in vegetables and seafood; which has a strong flavor and taste because of the fermentation process that characterizes most of the Korean dishes as they are enriched with flavors and can be preserved for long time (Kim, 2016). Their cooking techniques are based on fermentation and steamed, blanching, pickling and raw intake (Huang, 2003).

Korean food industry demonstrates a decline in the American fast food industry and its consumption perceiving its traditional cuisine by retaining the conventional food (Chung, 2016) which makes it too difficult for Saudi students to adapt and accept. On the other hand, Middle Eastern style is based on high carbohydrate and fat such as meat consumed mainly from lamb which involves a long process of cooking and frying. It is also rich in spices and animal fat. Various studies conducted on Saudi population indicated that Saudi diet includes very low intake of fruit and vegetables while high processed food and sweetened beverages are generally preferred (Moradi-Lakeh, 2017). These explanations indicate complete opposite preference that might be the main reason behind not accepting the new taste, as it has been reported in previous studies that food familiarity was the major factor involved in cross-cultural differentiation (Torri, 2016).

Recent studies indicated that in Korean culture, fast and high calorie food is declining, while Asian's natural, organic slow-cooked food is rising (Kim, 2016). The shift in food consumption is further due to the increased intake of fruit and vegetables (Lee, 2005). Recently, Korean population is aware of the importance of healthy food and the strong relation between eating habits and chronic disease; this awareness was recognized because of the increasing number of healthy organic markets and the increasing number of sport centers as a result of governmental strategic responses in Korea (Lee, 2012). The shared new trend in both cultures by choosing healthy, natural and organic food might make the adaptation to Korean culture easy. The finding of the study presented that the majority of the individuals bought their food ingredients from Korean Markets indicating their preferences of healthy selection and choices. This study's finding is similar to the previous study which found that international students living in the United States lack consumption of their traditional food due to its poor quality, limited access, high cost and lack of time (Alakaam, 2015). This might be beneficial to encourage adaptation to the new food culture especially when moving to healthy habits like low intake of fast food and high intake of vegetables, fruit and organic food. This study has some limitations, although the survey reached all students who have been contacted through the Saudi cultural Mission in South Korea. However, there were some students who relied on their private expenses and did not receive the invitation email. The study focuses on specific eating behaviors such as type of cuisine, but it did not go in depth regarding ingredients which might be interesting to look at in future 
studies. In addition, the online survey that has been used to assess the subject's habit might have some limitation of missing answers and possibility of miss recording the best choices. Further study is recommended to reveal the dietary eating behavior of students living abroad as compared to the eating behaviors in their home country. Quantitative study is also needed to emphasize the students' opinion on food culture and possibilities to overcome barriers during their journey.

The study has important implications for students migrating to other countries, as it helps in providing both general and specific information regarding points that are needed to be considered when planning to travel for educational purposes. Besides, policy makers specifically those of the Saudi consulates may benefit from this study in counselling students regarding the food related issues found in other regions. Saudi government is further suggested to scrutinize students' needs in the international countries, to facilitate their period of education.

\section{Conclusion}

This study explored the influence of Korean food and culture on Saudi migrants and observed the changes in their eating habits. The study shows that it is important to get knowledge of food practices and preferences of international students from various ethnic groups to understand the effect of a new culture and identify the common and shared issues that they face. The findings highlighted diversity of dietary practices that raise the need of attention of providing nutritional policies and nutritional educational service to recognize the dietary needs of the international students. The study also raises the importance of increasing food choices availability in universities and colleges and perhaps international food within the Korean market and to ensure that international students feel content thus to attract more international students towards South Korea. Future studies need to explore the role of dietary acculturation on weight gain and other health measures among the international population.

\section{Acknowledgements}

The author is very thankful to all the associated personnel in any reference that contributed in/for the purpose of this research. The study is not funded through any source and the author declares no conflicting interests.

\section{Competing Interests Statement}

The authors declare that there are no competing or potential conflicts of interest.

\section{References}

Alakaam, A. A., Castellanos, D. C., Bodzio, J., \& Harrison, L. (2015). The factors that influence dietary habits among international students in the United States. JIS, 5, 104-120.

Aljaroudi, R. (2018). Exploring the Food Choices of Muslim Arab Immigrants in Canada. A thesis presented to the University Of Waterloo in fulfilment of the thesis requirement for the degree of Doctor of Philosophy in Public Health \& Health Systems.

Bharmal, N. H., McCarthy, W. J., Gadgil, M. D., Kandula, N. R., \& Kanaya, A. M. (2018). The Association of Religious Affiliation with overweight/obesity among south Asians: the mediators of atherosclerosis in south Asians living in America (MASALA) study. $J$ Relig Health, 57, 33-46. https://doi.org/10.1007/s10943-016-0290-z

Brittin, H. C., \& Obeidat, B. A. (2011). Food practices, changes, preferences and acculturation of Arab students in US universities. Int J Consum Stud., 35, 552-559. https://doi.org/10.1111/j.1470-6431.2011.01023.x

Casali, M. E., Borsari, L., Marchesi, I., Borella, P., \& Bargellini, A. (2018). Lifestyle and food habits changes after migration: a focus on immigrant women in Modena (Italy). Ann Ig., 27, 10.

Cho, C. H. (2010). Korean wave in Malaysia and changes of the Korea-Malaysia relations. MJMS, 12, 1-4.

Chung, H. K., Yang, H. J., Shin, D., \& Chung, K. R. (2016). Aesthetics of Korean foods: The symbol of Korean culture. J Ethn Foods, 3, 178-188. https://doi.org/10.1016/j.jef.2016.09.001

Fadzlillah, N. A., Man, Y. B., Jamaludin, M. A., Rahman, S. A., \& Al-Kahtani, H. A. (2011). Halal food issues from Islamic and modern science perspectives. In 2nd International Conference on Humanities, Historical and Social Sciences 2011 (Vol. 17, pp. 159-163).

Guendelman, M. D., Cheryan, S., \& Monin, B. (2011). Fitting in but getting fat: Identity threat and dietary choices among US immigrant groups. Psychol Sci., 22, 959-967. https://doi.org/10.1177/0956797611411585

Holmboe-Ottesen, G., \& Wandel, M. (2012). Changes in dietary habits after migration and consequences for health: a focus on South Asians in Europe. Food Nutr Res., 56, 18891. 
https://doi.org/10.3402/fnr.v56i0.18891

Huang, T. T., Harris, K. J., Lee, R. E., Nazir, N., Born, W., \& Kaur, H. (2003). Assessing overweight, obesity, diet, and physical activity in college students. $J$ Am Coll Health, 52, 83-86. https://doi.org/10.1080/07448480309595728

Kim, S. H., Kim, M. S., Lee, M. S., Park, Y. S., Lee, H. J., Kang, S. A., .. \& Lee, Y. E. (2016). Korean diet: characteristics and historical background. J Ethn Foods, 3, 26-31. https://doi.org/10.1016/j.jef.2016.04.001

Kweon, S. Y., \& Yoon, S. J. (2006). Recognition and preference to Korean traditional food of Chinese at Seoul residence. J Korean Soc Food Cult., 21, 17-30.

Lee, H. S., Duffey, K. J., \& Popkin, B. M. (2012). South Korea's entry to the global food economy shifts in consumption of food between 1998 and 2009. Asia Pac J Clin Nutr., 21, 618.

Lee, M. J., Popkin, B. M., \& Kim, S. (2002). The unique aspects of the nutrition transition in South Korea: the retention of healthful elements in their traditional diet. Public Health Nutr., 5, 197-203. https://doi.org/10.1079/phn2001294

MacroTrends. (2019). South Korea Immigration Statistics 1960-2019. 2019. Retrieved from https://www.macrotrends.net/countries/KOR/south-korea/immigration-statistics

Moradi-Lakeh, M., El Bcheraoui, C., Afshin, A., Daoud, F., AlMazroa, M. A., Al Saeedi, M., ... \& Mokdad, A. H. (2017). Diet in Saudi Arabia: findings from a nationally representative survey. Public Health Nutr., 20, 1075-1081. https://doi.org/10.1017/S1368980016003141

Sucher, K. P., Kittler, P. G., \& Nelms, M. (2016). Food and culture. Nelson Education.

Tarraf, D., Sanou, D., \& Giroux, I. (2017). Immigration and Food Insecurity: The Canadian Experience-A Literature Review. People's Movements in the 21st Century: Risks, Challenges and Benefits. https://doi.org/10.5772/66824

Taylor, C., \& Albasri, W. (2014). The impact of Saudi Arabia King Abdullah's scholarship program in the US. JSS, 2, 109. https://doi.org/10.4236/jss.2014.210013

Thomas, R. L., Chiarelli-Helminiak, C. M., Ferraj, B., \& Barrette, K. (2016). Building relationships and facilitating immigrant community integration: An evaluation of a Cultural Navigator Program. Eval Program Plann, 55, 77-84. https://doi.org/10.1016/j.evalprogplan.2015.11.003

Torneo, A. R. (2016). Immigration policies and the factors of migration from developing countries to South Korea: An empirical analysis. Int Migr., 54, 139-158. https://doi.org/10.1111/imig.12246

Torri, L., Jeon, S. Y., Piochi, M., Morini, G., \& Kim, K. O. (2017). Consumer perception of balsamic vinegar: A cross-cultural study between Korea and Italy. Food Res Int., 91, 148-160. https://doi.org/10.1016/j.foodres.2016.12.003

\section{Copyrights}

Copyright for this article is retained by the author(s), with first publication rights granted to the journal.

This is an open-access article distributed under the terms and conditions of the Creative Commons Attribution license (http://creativecommons.org/licenses/by/4.0/). 